\title{
Quality of Life in Allergic Rhinitis Patients
}

\author{
Geetanjali Chauhan $_{1}$, Prof. C. P. Khokhar 2
}

\section{ABSTRACT:}

The quality of life is an individual's perceptions of their position in life in the context of the culture and value systems in which they live and in relation to their goals, expectations, standards and concerns. The term "health-related quality of life" refer to the physical, psychological, and social domains of health, seen as distinct areas that are influenced by a person's experiences and perceptions. In Allergic rhinitis patients, (HRQL) issues include learning impairment, inability to integrate with peers, anxiety and family dysfunction. The pathophysiology of allergic rhinitis often disrupts sleep, leading to fatigue, irritability, memory deficits, daytime sleepiness and depression. The total burden of this disease goes beyond impairment of physical and social functioning. Deleterious impact of allergic rhinitis-related to sleep disorders has negative effect on patients capacity to perform activities of daily living is an important component of the morbidity of the disease. With an accurate diagnosis, there is various available treatment that can reduce the burden of allergic rhinitis. The present investigation has been conducted to study quality of life in allergic rhinitis patients a total sample of 200 (100 allergic rhinitis patients and 100 non rhinitis subjects) has been randomly drawn from the clinics and hospitals of district Hardwar and as per the availability of the patients for measuring quality of life, the WHOQOL-BREF Questionnaire was used. The scale has four dimensions i.e. physical, psychological, social and environment. T- Test has been used to find out significant mean differences. Results show a significant difference between allergic rhinitis patients and non rhinitis subjects in terms of four dimensions i.e. physical, psychological, social and environment. However in other comparison there were no significance difference between gender and age.

Keywords: Life, Allergic Rhinitis Patients

\section{INTRODUCTION:}

Respiratory allergy is prevalent among all populations with increasing trend all over the world. The gravity of the situation can be perceived by looking at the epidemiological data available across the global. Epidemiological studies carried out in different countries indicate the prevalence of respiratory allergy as $15-30 \%$. A survey conducted in Finland shows a prevalence of around $14 \%$ allergic rhinitis and $.5 \%$ asthma.

\footnotetext{
${ }^{1}$ Research scholar, Gurukul Kangri University, Haridwar, Rohalki, Bahadrabad, Haridwar, Uttarakhand

${ }^{2}$ Prof. Gurukul kangri university, Haridwar, Rohalki, Bahadrabad, Haridwar, Uttarakhand
}

(C) 2015, G Chauhan, C Khokhar; licensee IJIP. This is an Open Access Research distributed under the terms of the Creative Commons Attribution License (http://creativecommons.org/licenses/by/2.0), which permits unrestricted use, distribution, and reproduction in any Medium, provided the original work is properly cited. 


\section{Quality of Life In Allergic Rhinitis Patients}

A recent survey carried out in India shows that 20-30\% of the population suffers from allergic rhinitis and that $15 \%$ develop asthma. However a study carried over 30 years ago in Delhi reported around 10\%allergic rhinitis and 1\% asthma (Anand B. Singh and Pawan Kumar, 2003; Pekkanen J. et al, 1997) Allergic rhinitis is a chronic inflammatory disorder of the nasal passages. It affects approximately $20 \%$ of the population, is a significant health and economic burden, and severely impairs quality of life.( Anju Tripathi \& Roy Patterson, 2001)

Runny itchy nose, sneezing and nasal congestion sound familiar. These are the common place symptoms of rhinitis, which we have all experienced at some point in our lives during a cold these are also the identical symptoms for allergic rhinitis -up to 30 percent of the adult population suffer from allergies. Allergic rhinitis may be classified as seasonal (i.e., symptoms during a specific time of the year) or perennial (i.e. symptoms occur year round). Seasonal rhinitis is typically caused by identifiable outdoor allergens, such as tree, grass and weeds pollens as well as moulds. Perennial rhinitis may be precipitated by dust mites, cockroaches, animal proteins and fungi (Randy A. Sansons, 2011).

The quality of life is a person perception of their position in life in the context of the culture and value systems in which they live and in relation to their goals, expectations, standards and concerns. (Gregory et al, 2009).

Health related quality of life refer to the physical, psychological, and social domains of health, seen as distinct areas that are influenced by a person's experiences and perceptions. (Marcia A. Testa and Donald G. Simonson, 2008; Meltzer EO, 2001).

Allergic rhinitis is a common disorder, which represents a considerable burden both on individual patients and society (Bousquet et.al, 2001). It is associated with bothersome symptoms, which may impair usual daily activities, quality of sleep and productivity (Crystal et. al, 2000). Frequently, allergic rhinitis is associated with co morbidities including asthma (Spector SL., 1997; Leynaert B.et.al, 2000). Overall, the quality of life is significantly impaired in subjects with allergic rhinitis (Bosquet J. et. Al, 1994; Leynaert B.et.al, 2000) but can be improved by treatment (Tripathi A. and Peterson R., 2001). Indeed, early detection and optimal treatment are emphasized in guidelines (Bousquet et.al, 2001). However, the condition may frequently be trivialized (by the patient) and/or unrecognized (by the physician), resulting in the inadequate control of symptoms. In the UK, only $18 \%$ of subjects with rhinitis had visited their general practitioner, over the preceding 2 yrs, concerning their hay fever (Jones NS.et. al, 1998). A recent study in France showed that $19 \%$ of 230 patients with typical symptoms of allergic rhinitis had never consulted a physician for their nasal problem (Didier A. et.al, 1999). The total burden of this disease goes beyond impairment of physical and social functioning. It has also a financial impact, which becomes greater when we consider the evidence that allergic rhinitis is a possible casual factor of co morbidities, such as asthma and sinusitis. Nasal obstruction, the most prominent symptom is associated with sleep disorders, which can have a profound effect on mental health, learning, behavior and attention. Finally, allergic rhinitis -a chronic condition that affects adults, adolescents and children is often under diagnosed or inadequately treated. In general, the patients feel inconvenienced by the symptoms per se, particularly by the nasal obstruction, rhino rhea and sneezing. They are irritated by not being able to sleep well at night 


\section{Quality of Life In Allergic Rhinitis Patients}

and often being exhausted during the day. They also experience non-nasal symptoms that cause discomfort, such as thirst, inability to concentrate and headache. They consider certain practical problems quite irritating, such as the need to carry tissues or handkerchiefs and to frequently blow their nose. They present with limitations in their activities of daily living, which leaves them frustrated and irritated. Although adolescents experience problems similar to those of the adults, they present greater difficulty in concentrating, particularly on their school work (Camelo-Nunes IC and Sole D, 2010). Younger children, however, present a slightly different profile: they feel uncomfortable with symptoms and practical problems, such as having to carry tissues or handkerchiefs and to take medicine; however, they tend to experience less limitation in their activities of daily living and do not exhibit the emotional disturbance experienced by adults and adolescents (Juniper EF et al, 1999).

Sleep disorders can impair the quality of life, leading to fatigue, irritability, memory deficits and daytime sleepiness (Ibiapina Cda C et al, 2008; Juniper EF et al, 2003). Sleep disorders also have a significant effect on mental health and can cause psychiatric diseases, depression and anxiety (Chang PP et al, 1997). In addition, respiratory events associated with sleep disorders, in childhood and adolescence, are associated with greater frequency of disorders related to learning, behavior and attention (Owens J, 1998; Gozal D., 1998). Sleep disorders related to the inability to breathe well during the night are in fact commonly observed in patients with allergic rhinitis. Studies on this topic have shown not only that the impairment of the sleep has an important impact on social life, professional skills and learning of the patients but also that the treatment of allergic rhinitis can have a beneficial effect, improving the quality of sleep and, consequently, reducing all limitations secondary to the sleep disorders (Hughes K. et al, 2003; Mansfield LE. et al, 2004).

Impact on learning and social life is frequently seen as a trivial and temporary disease or, yet, as a less severe disease when compared with asthma. Allergic rhinitis is capable of markedly altering the quality of life of the patients, as well as their performance, learning and productivity (Ibiapina Cda C. et al, 2008; Tanner LA et al, 1999; Schoenwetter WF et al 2004). Memory and learning are functional characteristics that can be impaired in patients with allergic rhinitis, leading to a crucial impact on their intellectual performance. In fact, patients with allergic rhinitis whose symptoms are not adequately controlled can have learning problems, either due to direct interference of the symptoms or due to impaired quality/quantity of nighttime sleep, resulting in daytime fatigue (Nathan RA., 2007). The home life of many patients is affected by allergic rhinitis. Children with allergic rhinitis can experience feelings of total isolation, even within their families, since the presence of allergens frequently hinders their participation in family activities, such as picnics, as well as preventing them from playing with pets and going camping (Meltzer EO., 2001). The social effect of allergic rhinitis is not restricted to the family sphere. In school, children with allergic rhinitis can present emotional disturbance caused by the learning impairment that commonly accompanies allergic rhinitis or by the limitations of activities imposed due to the need to avoid contact with allergens. As a result, they are unable to achieve 


\section{Quality of Life In Allergic Rhinitis Patients}

complete and unrestricted integration with their peers, and emotional disturbances arise. Allergic rhinitis is commonly associated/9with other respiratory diseases, and the cost resulting from these co morbidities increases even more the socioeconomic impact of the disease (Schoenwetter WF et al, 2004; Nathan RA, 2007). This impact comprises direct costs, generated by the use of the health care system, and by indirect costs, associated with the loss of economic productivity. Therefore, people with rhinitis or asthma need to cope with the immediate and long-term burdens related to these diseases, which habitually affect their activities of daily living. They often have to choose how to distribute their financial resources-normally directed to daily needs, such as food and clothing-to pay for the medical care necessary to improve their health status (Bousquet J. et al, 2001). There have been many fewer studies on the economic impact imposed on people with allergic rhinitis than on that imposed on those with asthma. It is estimated that allergic rhinitis results in impaired productivity or job loss in approximately half of all patients (Blaiss MS., 2003).

\section{METHODS}

The study includes allergic rhinitis patients and non rhinitis subjects. The data was drawn from government and private hospitals and clinics of district Hardwar and its adjoining districts.

200 subjects (100 rhinitis subjects and 100 non rhinitis subjects) of the present investigation were selected. Subject of non rhinitis group were taken keeping in view, the status, age, sex, education and economic background of rhinitis group. Subjects completed the Hindi version of WHOQ BREF containing 26 items which measures physical health, psychological health, social relationship and environmental health.

Statistical analysis

The present investigation has been conducted to study quality of life in allergic rhinitis patients. The sample include 100 (rhinitis patients), 100 (non rhinitis subjects.) again sample divided according to gender, age group 20-30 and 40 above age and to asses effect of quality of life in allergic rhinitis and non rhinitis patients in different dimensions. WHOQOL BEF scale Administered for assessing their quality of life in physical health, psychological function, social relationship and environment. Data analyzed with the help of t-test. Result indicated that the quality of life in allergic rhinitis patients (male, female) were decreased in comparison to non rhinitis (male, female) this showed there was significance difference between rhinitis patients and non rhinitis subjects in terms of quality of life On the other hand the quality of life of rhinitis females and rhinitis males were similar with respect to quality of life Significance difference were not found to be related with gender. It indicated that gender of the respondents was not capable in affecting the quality of life. 


\section{RESULTS}

Quality of life in allergic rhinitis females and non rhinitis females was compared. The t- value for physical health was obtained 5.23which is significant on .05 and .01 level. The t- value for Psychological function dimension was obtained 6.19 Which is significant on .05 and .01 level. The $\mathrm{t}$ - value for social relationship was obtained 3.92 which is significant on .05 and .01 level. The t- value for Environment was obtained 8.89 which is significant on .05 and .01 level. (Table1).

Table 1

\begin{tabular}{|l|r|r|r|r|r|r|}
\hline \multicolumn{7}{|c|}{ Quality of life } \\
\hline Quality of life & $\begin{array}{l}\text { Mean } \\
\text { (allergic } \\
\text { rhinitis) } \\
\text { female }\end{array}$ & $\begin{array}{l}\text { Mean } \\
\text { Non } \\
\text { rhinitis } \\
\text { female }\end{array}$ & $\begin{array}{l}\text { SD } \\
\text { allergic } \\
\text { rhinitis }\end{array}$ & $\begin{array}{l}\text { SD non } \\
\text { rhinitis } \\
\text { female }\end{array}$ & SE d & $\begin{array}{l}\text { t test } \\
\text { value }\end{array}$ \\
\hline Physical health & 20.3 & 24.28 & 4.02 & 3.61 & 0.76 & 5.23 \\
\hline $\begin{array}{l}\text { psychological } \\
\text { function }\end{array}$ & 17.12 & 22.26 & 4.85 & 3.32 & 0.83 & 6.19 \\
\hline Social relationship & 9.1 & 11.14 & 2.58 & 2.67 & 0.52 & 3.92 \\
\hline Environment & 21.18 & 27.94 & 4.65 & 4.8 & 0.76 & 8.89 \\
\hline
\end{tabular}

Distribution of sample between allergic rhinitis female and non rhinitis female

Table 2

\begin{tabular}{|c|c|c|c|c|c|c|}
\hline \multicolumn{7}{|c|}{ Quality of life } \\
\hline Quality of life & $\begin{array}{l}\text { Mean } \\
\text { (allergic } \\
\text { rhinitis) } \\
\text { male }\end{array}$ & $\begin{array}{l}\text { Mean } \\
\text { non } \\
\text { rhinitis } \\
\text { male }\end{array}$ & $\begin{array}{l}\text { SD } \\
\text { allergic } \\
\text { rhinitis } \\
\text { male }\end{array}$ & $\begin{array}{l}\text { SD non } \\
\text { rhinitis } \\
\text { male }\end{array}$ & SE d & $\begin{array}{l}\text { t test } \\
\text { value }\end{array}$ \\
\hline Physical health & 20.06 & 25.06 & 4.26 & 3.71 & 0.79 & 6.26 \\
\hline $\begin{array}{l}\text { psychological } \\
\text { function }\end{array}$ & 17.68 & 22.58 & 4.02 & 3.81 & 0.78 & 6.25 \\
\hline Social relationship & 9.42 & 11.52 & 2.62 & 2.76 & 0.53 & 3.96 \\
\hline Environment & 21.6 & 27.88 & 4.34 & 4.38 & 0.87 & 7.21 \\
\hline
\end{tabular}

Distribution of sample between allergic rhinitis male and non rhinitis male 
Table 3

\begin{tabular}{|c|c|c|c|c|c|c|}
\hline \multicolumn{7}{|c|}{ Quality of life } \\
\hline Quality of life & $\begin{array}{l}\text { Mean } \\
\text { (allergic } \\
\text { rhinitis) } \\
\text { female }\end{array}$ & $\begin{array}{l}\text { mean } \\
\text { allergic } \\
\text { rhinitis } \\
\text { male }\end{array}$ & $\begin{array}{l}\text { SD } \\
\text { allergic } \\
\text { rhinitis } \\
\text { female }\end{array}$ & $\begin{array}{l}\text { SD } \\
\text { allergic } \\
\text { rhinitis } \\
\text { male }\end{array}$ & $\mathrm{SE} \mathrm{d}$ & $\begin{array}{l}\text { t test } \\
\text { value }\end{array}$ \\
\hline Physical health & 20.3 & 20.6 & 4.02 & 4.26 & 0.82 & 0.29 \\
\hline $\begin{array}{l}\text { psychological } \\
\text { function }\end{array}$ & 17.12 & 17.68 & 4.85 & 4.02 & 0.89 & 0.62 \\
\hline Social relationship & 9.1 & 9.44 & 2.58 & 2.62 & 0.51 & 0.57 \\
\hline Environment & 21.18 & 21.6 & 4.65 & 4.34 & 0.8 & 0.52 \\
\hline
\end{tabular}

Distribution of sample according to gender

Table 4

\begin{tabular}{|c|c|c|c|c|c|c|}
\hline \multicolumn{7}{|c|}{ quality of life (age group 20-30 n=42, age group 40 above $n=37$ ) } \\
\hline Quality of life & $\begin{array}{l}\text { mean } \\
\text { rhinitis } \\
20-30 \text { age } \\
\text { male, } \\
\text { female }\end{array}$ & $\begin{array}{l}\text { mean } \\
\text { rhinitis } \\
40 \text { above } \\
\text { age group } \\
\text { male, } \\
\text { female }\end{array}$ & $\begin{array}{l}\text { SD } \\
\text { rhinitis } \\
20-30 \\
\text { age }\end{array}$ & $\begin{array}{l}\text { SD } \\
\text { rhinitis } \\
40 \\
\text { above } \\
\text { age }\end{array}$ & SE d & $\begin{array}{l}\text { t test } \\
\text { value }\end{array}$ \\
\hline Physical health & 20.73 & 19.35 & 3.55 & 4.84 & 4.51 & 0.3 \\
\hline $\begin{array}{l}\text { psychological } \\
\text { function }\end{array}$ & 18.02 & 16.1 & 3.81 & 5 & 3.86 & 0.5 \\
\hline Social relationship & 9.73 & 9 & 2.77 & 2.42 & 2.1 & 0.34 \\
\hline Environment & 21.76 & 20.91 & 4.71 & 4.44 & 4.79 & 0.17 \\
\hline
\end{tabular}

Distribution of sample according to age group

Quality of life in allergic rhinitis females and non rhinitis females was compared. In Physical health domain $\mathrm{t}$ - value was obtained 6.26 which is significant on .05 and .01 level. The t- value for Psychological function dimension was obtained 6.25 which is significant on .05 and .01 level. The t- value for social relationship was obtained 3.96 which is significant on .05 and .01 level. The t- value for Environment was obtained 7.21 which is significant on .05 and .01 level (Table2).

Rhinitis females and males were similar with respect to four domains of quality of life i.e. physical, psychological, and social and environment. Obtained t- value is non significant on .05 and .01 level. It indicated that gender and age groups of the respondents was not capable in affecting the quality of life (Table- 3,4 ) 


\section{Quality of Life In Allergic Rhinitis Patients}

\section{DISCUSSION}

Health -related quality of life refer to the physical, psychological, and social domains of health, seen as distinct areas that are influenced by a person's experiences and perceptions. Patients with allergic rhinitis were shown to experience limitations in daily activities, as well as changes in mood and cognitive behavior. Quality of life in allergic rhinitis patients was assessed by WHOQOL four domains. In general rhinitis patients having low physical activity negative felling and low self esteem, lack of social support, unfavorable environment in comparison to non rhinitis subjects. WHOQOL is a major outcome in allergic rhinitis represents a global health problem because it interferes with psychological well being, activities of daily living and affects social as economic outcomes. There is growing awareness of how allergic can affect patient's quality of life work or school performance, and emotional well being. Besides physical symptoms, patients may exhibit fatigue, psychomotor sluggishness, irritability and mood and cognitive disturbances this combination of physical, emotional and functional problems may diminish quality of life. The quality of life is a person`s perception of their position in life in the context of the culture and value systems in which they live and in relation to their goals, expectations, standards and concerns. Rhinitis females and males were similar with respect to four dimensions of quality of life i.e. physical, psychological and social and environment. Significance difference was not found to be related with gender and age group. It indicated that gender and age group of the respondents was not capable in affecting the quality of life.

\section{CONCLUSION}

In conclusion this study provides further evidence that allergic rhinitis patient's quality of life was worse than non rhinitis subjects. The allergic rhinitis patients showed significantly lower mean score on physical, psychological, social and environment. Allergic rhinitis is a common respiratory allergy among all population which impairs quality of life of Patients due to discomforting symptoms of this disease. Allergic rhinitis impairs the quality of life of persons in different Domains. Allergic rhinitis patients feel fatigue, pain, and discomfort, lack of sleep and rest. Patients feel faulty bodily image, lack of concentration, suffers from learning impairment, anxiety and family dysfunction; disrupt social relationship, inability to integrate with peers, receiving low quality of support from families, friends and others. Physical environment (pollution / noise /traffic and climate are worse. patients do not feel very healthy and do not full of energy to take on their daily activities. People are not satisfied with their lives. These findings indicated that allergic patients had a greater tendency to depend on medical substance due to physical inactivity, poorer psychological adjustment, social anxiety and shyness in adults and a lower ability to deal with environmental pressure. In total, the findings suggest that the allergic patients had poorer overall psychological health than the non rhinitis subjects. 


\section{Quality of Life In Allergic Rhinitis Patients}

\section{REFERENCES}

1. Anand B. Singh and Pawan Kumar (2003). Aeroallergens in clinical practice of allergy in India, An overview. Allegric environ med, Aug;10:131-136.

2. Anju Tripathi and Roy Petterson (2001). Impact of allergic rhinitis treatment on quality of life. Pharmcoeconomic, Vol 19, issue 9: 891-899.

3. Blaiss MS. (2003). Important aspects in management of allergic rhinitis: compliance, cost, and quality of life. Allergy Asthma Proc, 24(4):231-8.

4. Bousquet J, Bullinger M, Fayol C, Marquis P, Valentin B \& Burtin B (1994). Assessment of quality of life in patients with perennial allergic rhinitis with the French version of the SF-36 Health Status Questionnaire. J Allergy Clin Immunol. 94:182-188.

5. Bousquet J, Van Cauwenberge P \& Khaltaev N (2001). Aria Workshop Group; World Health Organization. Allergic rhinitis and its impact on asthma. J Allergy Clin Immunol. 108(5 Suppl):S147-334.

6. Camelo-Nunes IC and Sole D (2010). Allergic Rhinitis: indicators of quality of life. $J$ Bras Pneumol. Jan-F eb;36(1):124-33.

7. Chang PP, Ford DE and Mead LA (1997). Insomnia in young men and subsequent depression. The Johns Hopkins Precursors Study. Am J Epidemiol. 146(2):105-14.

8. Crystal-Peters J, Crown WH, Goetzel RZ \& Schutt DC (2000). The cost of productivity losses associated with allergic rhinitis. Am J Manag Care. 6:373-378.

9. Didier A, Chanal I, Klossek JM \& Mathieu J. (1999). La rhinite allergique: le point de vue du patient. Revue Française Allergologie. 39:171-185.

10. Gozal D (1998). Sleep-disordered breathing and school performance in children. Pediatrics. 102(3 Pt 1):616-20.

11. Gregory, Derek and Johnston (2009). Quality of Life. Dictionary of Human Geography (5th ed.). Oxford: Wiley-Blackwell. ISBN 978-1-4051-3287-9

12. Hughes K, Glass C, Ripchinski M et al. (2003). Efficacy of the topical nasal steroid budesonide on improving sleep and daytime somnolence in patients with perennial allergic rhinitis. Allergy. 58(5):380-5.

13. Ibiapina Cda C, Sarinho ES, Camargos PA, Andrade CR and Cruz Filho AA (2008). Allergic rhinitis: epidemiological aspects, diagnosis and treatment. J Bras Pneumol. 34(4):230-40.

14. Jones NS, Smith PA, Carney AS \& Davis A (1998). The prevalence of allergic rhinitis and nasal symptoms in Nottingham. Clin Otolaryngol.23:547-554.

15. Juniper EF, Rohrbaugh T, and Meltzer EO (2003). A questionnaire to measure quality of life in adults with nocturnal allergic rhinoconjunctivitis. J Allergy Clin Immunol. 111(3):484-90.

16. Juniper EF, Thompson AK, Ferrie PJ and Roberts JN (1999). Validation of the standardized version of the Rhinoconjunctivitis Quality of Life Questionnaire. J Allergy Clin Immunol. 104(2 Pt 1):364-9. 


\section{Quality of Life In Allergic Rhinitis Patients}

17. Leynaert B, Bousquet J, Neukirch C, Liard R \& Neukirch F (1999). Perennial rhinitis: an independent risk factor for asthma in nonatopic subjects: results from the European Community Respiratory Health Survey. J Allergy Clin Immunol.104:301-304.

18. Leynaert B, Neukirch C, Liard R, Bousquet J \& Neukirch F (2000). Quality of life in allergic rhinitis and asthma. A population-based study of young adults. Am J Respir Crit Care Med.162:1391-1396.

19. Mansfield LE, Diaz G, Posey CR \& Flores-Neder J (2004). Sleep disordered breathing and daytime quality of life in children with allergic rhinitis during treatment with intranasal budesonide. Ann Allergy Asthma Immunol. 92(2):240-4.

20. Marcia A. Testa, Donald C. and Simonson (2008). Assessment of quality of life outcomes. The new England journal of medicine. Aug; vol334 no 13:835-840.

21. Meltzer EO (2001). Quality of life in adults and children with allergic rhinitis. J Allergy Clin Immunol. Jul;108(1 Suppl):S45-53.

22. Nathan RA (2007). The burden of allergic rhinitis. Allergy Asthma Proc. 28(1):3-9.

23. Owens J, Opipari L, Nobile C and Spirito A (1998). Sleep and daytime behavior in children with obstructive sleep apnea and behavioral sleep disorders. Pediatrics. 102(5):1178-84.

24. Pekkanen et al (1997). Prevalence of asthma symptoms in video and written questionnaires among children in four regions of Finland. Eur respire J; 10, 1784-1794.

25. Randy A. Sansone (2011). Allergic Rhinitis and its Relationships with Anxiety and Mood Syndromes. Innov Clin Neurosci. July; 8(7):12-17.

26. Schoenwetter WF, Dupclay L Jr, Appajosyula S, Botteman MF \& Pashos CL (2004). Economic impact and quality-of-life burden of allergic rhinitis. Curr Med Res Opin. 20(3):305-17.

27. Spector SL (1997). Overview of comorbid associations of allergic rhinitis. J Allergy Clin Immunol. 99:S773-S780.

28. Tanner LA, Reilly M, Meltzer EO, Bradford JE \& Mason J (1999). Effect of fexofenadine HCI on quality of life and work, classroom, and daily activity impairment in patients with seasonal allergic rhinitis. Am J Manag Care. 5(Suppl 4):S235-S47. 